\title{
Regulatory mechanisms of intestinal folate uptake in a rat model of folate oversupplementation
}

\author{
Som Dev, Nissar Ahmad Wani and Jyotdeep Kaur* \\ Department of Biochemistry, Postgraduate Institute of Medical Education and Research, Chandigarb 160 012, India
}

(Received 7 May 2010 - Revised 14 September 2010-Accepted 29 September 2010 - First published online 23 November 2010)

\section{Abstract}

Folic acid is essential for numerous biological functions, ranging from nucleotide biosynthesis to the remethylation of homocysteine. Folic acid is unable to cross the biological membranes by simple diffusion, so there exists a well-developed epithelial folate transport system for the regulation of normal folate homeostasis in the intestine. Any perturbances in the folate uptake system might lead to a state of folate deficiency, which in turn is strongly associated with the risk of various cancers, birth defects and CVD. Countries with obligatory folate fortification of food (USA and Canada) have documented a significant decrease in neural tube defects in newborns. However, the effect of folate oversupplementation on the intestinal absorption of folic acid has not been studied. We studied the process of folate transport and the expression of folate transporters in the rat intestine after folate oversupplementation. Rats were oversupplemented with tenfold the normal requirement of folic acid for periods of 10 and $60 \mathrm{~d}$. Folate uptake in intestinal brush-border membrane vesicles followed saturable kinetics with $\mathrm{pH}$ optimum at 5.5. Acute, but not chronic, folate oversupplementation led to a significant downregulation in intestinal folate uptake at acidic $\mathrm{pH}$ optima and was associated with a decrease in $V_{\max }$ without any significant change in the $K_{\mathrm{m}}$ of the folate uptake process. The decrease in folate uptake was also associated with the down-regulation in the protein levels of major folate transporters, proton-coupled folate transporter (PCFT) and reduced folate carrier (RFC), without altering their mRNA levels. Hence, it was concluded that acute folate oversupplementation results in a significant decrease in intestinal folate uptake by down-regulating the expressions of RFC and PCFT, via some post-transcriptional or translational mechanisms.

\section{Key words: Folic acid: Folate transport: Proton-coupled folate transporter: Reduced folate carrier: Folate oversupplementation}

Folic acid is a water-soluble vitamin (vitamin $\mathrm{B}_{9}$ ) and is required to be obtained from exogenous sources by man and other mammals. It is essential for the synthesis of amino acids and nucleic acids ${ }^{(1,2)}$. There exists a well-developed epithelial folate transport system for the regulation of normal folate homeostasis in the intestine. These systems have been elucidated and mechanisms of carrier-mediated absorption of folic acid have been reported $^{(3-5)}$. Reduced folate carrier (RFC or SLC19A1) and recently discovered proton-coupled folate transporter (PCFT), earlier called haem carrier protein 1, in the intestine have been found to be responsible for the transport of folate across the intestine ${ }^{(3,6)}$. The RFC is an integral protein of approximately $65 \mathrm{kDa}$ in man and approximately $58 \mathrm{kDa}$ in rats $^{(7)}$, which mediates cellular uptake of reduced folates and antifolates and is ubiquitously expressed ${ }^{(8)}$. The characteristics of folate transport by the RFC across the intestine, liver, pancreas, kidney and colon include $\mathrm{pH}$ dependence, saturable uptake at low folate concentration and competition among various folate derivatives ${ }^{(4,9-11)}$. The human $\mathrm{RFC}$ shows an amino acid homology of 65.2 and $66.0 \%$ with its rat and mouse counterparts, respectively ${ }^{(12)}$. The transport of folate in the intestine is also mediated by the newly discovered PCFT, which has the characteristics of $\mathrm{pH}$ dependence, $\mathrm{Na}^{+}$independence and similar affinity for reduced and oxidised folates ${ }^{(3)}$. PCFT mRNA expression is also prominent in the liver, an organ that specifically possesses and stores maximum folate, along with the kidney, colon, spleen and placenta ${ }^{(3)}$. It has been found that human PCFT protein has 459 amino acids and eleven putative membrane-spanning domains, and shares $91 \%$ similarity and $87 \%$ identity with both its mouse and rat counterparts ${ }^{(13)}$. In the kidney and liver, but not in the intestine, a family of high-affinity folate-binding proteins or folate receptors ( $\alpha$ and $\beta$ ) also transports the folates ${ }^{(14)}$. After absorption from the intestine, folic acid undergoes reduction and is methylated to 5-methyltetrahydrofolate

Abbreviations: BBM, brush-border membrane; BBMV, BBM vesicle; MES, 2-morpholinoethanesulphonic acid; PCFT, proton-coupled folate transporter; RFC, reduced folate carrier; rGAPDH, anti-rat glyceraldehyde 3-phosphate dehydrogenase; rPCFT, anti-rat PCFT; rRFC, anti-rat RFC.

*Corresponding author: J. Kaur, fax +91 172 2744401/2745078, email jyotdeep2001@yahoo.co.in 
before entry into the portal blood system. 5-Methyltetrahydrofolate acts as a methyl group donor for the synthesis of amino acids and nucleic acids ${ }^{(1,15)}$. Cellular folate concentrations are influenced by the availability of folate, transport efficiency, polyglutamylation and turnover of folate ${ }^{(6)}$.

Optimisation of body folate homeostasis led to a significant reduction in the incidence of neural tube defects ${ }^{(16,17)}$, and omphalocele ${ }^{(18)}$, conditions associated with folate deficiency. Epidemiological studies have suggested that benefits might also accrue from supplements of folic acid for CVD, Alzheimer's disease and certain types of cancers such as colorectal cancer ${ }^{(19-21)}$. Considering such benefits, a mandatory fortification of grain products with folic acid was instituted in many countries, including the USA and Canada. The intake of folic acid from fortified food $(100-200 \mu \mathrm{g} / \mathrm{d})$, together with the use of oral supplementation of folic acid $(400 \mu \mathrm{g})$, standard multivitamin preparations and consumption of nutrition bars, might create a state of folate oversupplementation ${ }^{(22)}$, amounting to an increase in folic acid intake above the upper tolerable level, i.e. $1000 \mu \mathrm{g}$ folic $\mathrm{acid} / \mathrm{d}^{(23)}$. This practice is occurring with little knowledge on the potential safety and physiological consequences of chronic intake of such a high dose of folic acid. The most well-known risk of exposure to high doses of folic acid is the possible masking of cobalamin deficiency in pernicious anaemia ${ }^{(24)}$. This is because folic acid may improve haematological indices but not the neurological disease of a prolonged cobalamin deficiency. Song et al. ${ }^{(25)}$ suggested that folate oversupplementation in rats accelerates cancer progression, while Achon et al. ${ }^{(26)}$ found no adverse effects of folate oversupplementation on one-carbon metabolism. However, the effect of folate oversupplementation on the regulation of various genes involved in folate metabolism and with one-carbon transfer reactions demands a thorough investigation. It has also been reported that, upon folate oversupplementation, unmetabolised folic acid in the plasma was associated with decreased natural killer cell cytotoxicity among postmenopausal women ${ }^{(27)}$. Results of two very recently conducted randomised, controlled trials have suggested no short- or long-term benefits of folic acid plus vitamin $\mathrm{B}_{12}$ on cardiovascular outcomes in patients with IHD. The authors have suggested that cardiovascular risk prediction by total plasma homocysteine concentration was confined to the homocysteine fraction that does not respond to $B$ vitamins ${ }^{(28)}$. As studies have mainly focused on the consequences of folic acid supplementation on one or the other disease, little is known regarding the regulation of the intestinal folate transport process during folate oversupplementation. A recent report has described the down-regulation of folate transporters in human intestinal and renal cells cultured with excess folic acid ${ }^{(29)}$. More recently, it has been observed that dietary folate oversupplementation decreases the expression of the RFC in an avian system ${ }^{(30)}$. However, such effects of dietary folate oversupplementation in a mammalian model have not been studied. Therefore, we planned the present study to delineate the regulatory mechanisms of dietary folate oversupplementation on the intestinal folate transport process in rats. We studied the effect of acute and chronic folate oversupplementation on the folate transport process in the intestinal brush-border membrane (BBM), and the mRNA and protein expression of the major folate transporters (PCFT and RFC).

\section{Methods and materials}

\section{Chemicals}

Radiolabelled $\left[3^{\prime}, 5^{\prime}, 7,9-{ }^{3} \mathrm{H}\right]$ folic acid, K salt with a specific activity of $24.0 \mathrm{Ci} / \mathrm{mmol}$, was purchased from Amersham Pharmacia Biotech (Hong Kong, China). ColorBurst ${ }^{\mathrm{TM}}$ electrophoresis marker (molecular weight 8000-220000) was purchased from Sigma Chemical Company (St Louis, MO, USA). NP-P Total RNA Extraction Kit was purchased from Taurus Scientific (Cincinnati, OH, USA). Moloney murine leukemia virus reverse transcriptase RevertAid $^{\mathrm{TM}}$ M-MuLV RT) kit was purchased from MBI Fermentas Life Sciences, Glen Burnie, MD, USA. RNAlater (RNA stabilisation solution) was obtained from Ambion, Inc. (Austin, TX, USA). Polyclonal primary antibodies, rabbit anti-rat RFC (rRFC) and anti-rat PCFT (rPCFT), were raised in rabbits in our laboratory. Horseradish peroxidase-labelled goat anti-rabbit IgG secondary antibodies were purchased from G Biosciences (St Louis, MO, USA). Metal-enhanced DAB substrate kit was purchased from Thermo Scientific (Rockford, IL, USA). Cryoprotected Lactobacillus casei bacterial strain (MTCC 1423) was purchased from IMTECH (Chandigarh, India).

\section{Rats and experimental diets}

Male albino rats (Wistar strain) ${ }^{(31)}, 1$ month old, weighing 60-80g ( $n$ 24) were obtained from the Central Animal House of the institute. Rats were housed in clean wire mesh cages with controlled temperature $\left(23 \pm 1^{\circ} \mathrm{C}\right)$ and humidity (45-55\%) and with a $12 \mathrm{~h}$ dark-12 h light cycle throughout the study. Rats were randomised into two groups of twelve animals each. Rats in group I were given semisynthetic diets containing a $2 \mathrm{mg}$ folic acid/ $\mathrm{kg}$ diet (control) and those in group II were given a folateoversupplemented rat diet, tenfold the requirement for rats, i.e. $20 \mathrm{mg}$ folic acid $/ \mathrm{kg}$ diet (oversupplemented) (Table 1). Six animals each from groups I and II received the treatment for $10 \mathrm{~d}$ (acute treatment) and the remaining six for $60 \mathrm{~d}$ (chronic treatment). The animals had free access to water. The body weight of the rats was recorded twice weekly. Animals from both groups were killed under anaesthesia, using sodium pentothal. Starting from the ligament of Treitz, two-thirds of the small intestine was removed, flushed with ice-cold saline and processed for the isolation of cells. 
Table 1. Composition of the diets

\begin{tabular}{lcc}
\hline Ingredients (per kg diet) & Control diet & Oversupplemented diet \\
\hline Casein $(\mathrm{g})$ & 180 & 180 \\
Starch $(\mathrm{g})$ & 265 & 265 \\
Sucrose $(\mathrm{g})$ & 265 & 265 \\
Cellulose $(\mathrm{g})$ & 110 & 110 \\
Salt mixture $(\mathrm{g})$ & 60 & 60 \\
Choline $(\mathrm{g})$ & 2 & 2 \\
Vitamin mixture (tablet) & 1 & 1 \\
Folic acid $(\mathrm{mg})$ & 2 & 20 \\
Vitamin K $(\mathrm{ml})$ & $1 \cdot 25$ & $1 \cdot 25$ \\
Maize oil $(\mathrm{ml})$ & 110 & 110 \\
& &
\end{tabular}

The protocol of the study was approved by the Institutional Animal Ethics Committee and the Institutional Biosafety Committee.

\section{Isolation of intestinal epithelial cells}

Intestinal epithelial cells were isolated following the method of Weiser ${ }^{(32)}$, with modifications ${ }^{(9)}$. The upper two-thirds of the small intestine was cut and flushed two to three times with $0.9 \%$ saline. One end of the intestine was tied with a thread and filled with rinsing buffer containing $1 \mathrm{~mm}$-dithiothreitol in normal saline. The rinsing buffer was then replaced with a solution consisting of $1.5 \mathrm{~mm}-\mathrm{KCl}, \quad 96 \mathrm{~mm}-\mathrm{NaCl}, 27 \mathrm{~mm}$-sodium citrate, $8 \mathrm{~mm}-$ $\mathrm{KH}_{2} \mathrm{PO}_{4}$ and $8 \mathrm{~mm}^{-N_{2}} \mathrm{HPO}_{4}$, and incubated at $37^{\circ} \mathrm{C}$ for $15 \mathrm{~min}$ in a beaker containing PBS. The intestine was then filled with a solution containing $1.5 \mathrm{~mm}$-EDTA and $0.5 \mathrm{~mm}$-dithiothreitol in PBS, and incubated at $37^{\circ} \mathrm{C}$ in a shaker at $100 \mathrm{rpm}$ for $30 \mathrm{~min}$; the solution was then collected for the isolation of total enterocytes. The collected cells were centrifuged at $800 \mathrm{~g}$ for $15 \mathrm{~min}$. The pellet contents were mixed with a Pasteur pipette and centrifuged at $800 \mathrm{~g}$ for $10 \mathrm{~min}$ after the addition of $5 \mathrm{ml}$ of cold PBS. Two more PBS washings were performed. These cells were then used for BBM isolation.

Preparation of brush-border membrane vesicles from isolated intestinal epithelial cells

BBMV were prepared from the isolated total intestinal cells from the control and folate-oversupplemented rats by the method of Kessler et al. ${ }^{(33)}$, with some modifications $^{(34)}$. The final pellet obtained was suspended in loading buffer (280 mm-mannitol, 20 mm-HEPES-Tris, $\mathrm{pH}$ 7.4) so as to obtain a protein concentration of approximately $5 \mathrm{mg} / \mathrm{ml}$. These BBMV were used to determine $\left[{ }^{3} \mathrm{H}\right]$ folic acid uptake and to analyse the PCFT and RFC protein levels.

\section{Transport of $\left[{ }^{3} \mathrm{H}\right]$ folic acid}

Uptake studies were performed at $37^{\circ} \mathrm{C}$, using the incubation buffer of $100 \mathrm{~mm}-\mathrm{NaCl}, 80 \mathrm{~mm}$-mannitol, $10 \mathrm{mm-HEPES}$,
$10 \mathrm{~mm}$-2-morpholinoethanesulphonic acid (MES), $\mathrm{pH} \mathrm{5.5,}$ and $0.5 \mu \mathrm{M}-\left[{ }^{3} \mathrm{H}\right]$ folic acid, unless otherwise mentioned. Isolated BBMV $(10 \mu \mathrm{l} ; 50 \mu \mathrm{g}$ protein) from the control and folate-oversupplemented diet-fed rats for different specific assays were added to the incubation buffer containing $\left[{ }^{3} \mathrm{H}\right]$ folic acid of known concentration. Reaction was stopped by adding an ice-cold stop solution containing 280 mm-mannitol, 20 mm-HEPES-Tris, pH 7·4, followed by rapid vacuum filtration. Non-specific binding to the filters was determined by residual filter counts after filtration of the incubation buffer and labelled substrate without vesicles $^{(34)}$. The radioactivity retained by the filters was determined by liquid scintillation counting (Beckman Coulter LS 6500, Kingsmead, London, UK). For the determination of the kinetic constants $K_{\mathrm{m}}$ and $V_{\max }$, transport of $\left[{ }^{3} \mathrm{H}\right]$ folic acid was measured by varying the concentration of $\left[{ }^{3} \mathrm{H}\right]$ folic acid from $0 \cdot 125$ to $3 \cdot 0 \mu \mathrm{M}$ and transforming the data according to the Lineweaver-Burk plot, as described earlier ${ }^{(35)}$.

\section{$R T-P C R$ analysis}

Total RNA from all animals was isolated from the upper $1 \mathrm{~cm}$ of jejunal tissues, using the total RNA extraction kit, and complementary DNA synthesis was carried out from the purified and intact total RNA according to the manufacturer's instructions. Primarily, the quality of RNA was assessed by electrophoresis using 1.5\% formaldehyde agarose gel. Analysis of RNA revealed the $28 \mathrm{~S}$ and $18 \mathrm{~S}$ RNA species and depicted the RNA to be in the intact form. Expressions of $\mathrm{r} R F C, \mathrm{r} P C F T$ and anti-rat glyceraldehyde 3-phosphate dehydrogenase (rGAPDH) were evaluated using sequence-specific primers corresponding to the sequence in the open reading frame. PCR mixture $(20 \mu \mathrm{l})$ was prepared in $1 \times$ PCR buffer consisting of $0.6 \mathrm{U}$ (10.06 nkatal) of Taq polymerase, $2 \mu \mathrm{M}$ of each primer for $\mathrm{rGAPDH}, \mathrm{r} P C F T$ and $\mathrm{r} R F C$ along with $200 \mu \mathrm{m}$ of each deoxynucleotide triphosphate. In optimised PCR, the initial denaturation step was carried out for $2 \mathrm{~min}$ at $95^{\circ} \mathrm{C}$. The denaturation, annealing and elongation steps were carried out, respectively, for $1 \mathrm{~min}$ at $94^{\circ} \mathrm{C}, 45 \mathrm{~s}$ at $64^{\circ} \mathrm{C}(P C F T)$ or $56^{\circ} \mathrm{C}(G A P D H)$ and $1 \mathrm{~min}$ at $72^{\circ} \mathrm{C}$ for thirty-five cycles. In the case of the $R F C$, the denaturation, annealing and elongation steps were carried out, respectively, for $30 \mathrm{~s}$ at $94^{\circ} \mathrm{C}, 30 \mathrm{~s}$ at $52 \cdot 1^{\circ} \mathrm{C}$ and $30 \mathrm{~s}$ at $72^{\circ} \mathrm{C}$ for forty-five cycles. The final extension step was carried out for $10 \mathrm{~min}$ at $72^{\circ} \mathrm{C}$. The primers were designed using Primer3 Input (version 0.4.0; USA). The sequences of the primers used are as follows ${ }^{(36)}$ :

Direction Primer sequence $\left(5^{\prime}\right.$ to $\left.3^{\prime}\right)$

$R F C$

Forward CATGCTAAGCGAACTGGTGA

Reverse TTTTCCACAGGACATGGACA

$P C F T$

Forward AAGCCAGTTATGGGCAACAC

Reverse GGATAGGCTGTGGTCAAGGA 


\section{GAPDH}

\section{Forward}

\section{CCTTCATTGACCTCAACTACAT}

Reverse CCAAAGTTGTCATGGATGACC

The expected PCR products of size 120, 300 and $400 \mathrm{bp}$ were obtained for $\mathrm{r} R F C, \mathrm{r} P C F T$ and $\mathrm{r} G A P D H$, respectively, when electrophoresed on $1.2 \%$ agarose gel. The densitometric analyses of the products were determined by using Scion image software (Frederick, MD, USA).

\section{Western blot analysis}

For protein expression studies, BBMV (100 $\mu \mathrm{g})$ isolated from epithelial cell preparations were resolved on $10 \%$ SDS-PAGE and transferred to a polyvinylidene fluoride membrane for $20 \mathrm{~min}$ at $15 \mathrm{~V}$. Western blotting was performed using the procedure described by Towbin et $a l{ }^{(37)}$, using polyclonal primary antibodies as rabbit rRFC (1:500 dilution) raised against a specific region of rat RFC synthetic peptide corresponding to amino acids $494-512^{(38)}$. The polyclonal antibodies against rPCFT (1:500 dilution) were raised against a specific region of rat PCFT synthetic peptide corresponding to amino acids 442-459. The immunogenic property of this peptide corresponding to PCFT protein was determined by using DNA STAR software (Madison, WI, USA). The primary antibodies against $\beta$-actin (1:400 dilution) were obtained from Santa Cruz Biotechnology (Santa Cruz, CA, USA). The secondary antibodies used were goat anti-rabbit IgG horseradish peroxidase-labelled antibodies (1:2000 dilutions). The quantification of blots was carried out by using Scion image.

\section{Estimation of folate by microbiological assay}

Folate estimations were determined by a microtitre plate assay using $L$. casei, as described earlier ${ }^{(9)}$. All the steps were carried out in aseptic conditions.

\section{Statistical analysis}

Each uptake assay was performed three times with four to six independent preparations from each group. Data were computed as means with their standard errors. Group means were compared using Student's $t$ test. The acceptable level of significance was $P<0.05$ for each analysis. The power of the study was $0 \cdot 80$.

\section{Results}

There was no significant change in the body weight of the folate-oversupplemented rats compared with the controls, during the course of the experiment both in acute and chronic treatments. At the time of killing, the mean body weights of the control and folate-oversupplemented rats in the acute group were 103 (SEM 2.4) and 105 (SEM 3.2) g, whereas those in the chronic folate oversupplementation group were 236 (sem 6.5) and 245 (sem 9.4) g, respectively.

\section{Serum folate levels}

Serum folate represents present folate intake, influenced by the diet, so it was important to determine the folate levels in all groups. The results showed that acute folate oversupplementation significantly increased the serum folate levels $(63.5$ (SEM 15.5) $\mathrm{ng} / \mathrm{ml}$ in the control group $v$. 140 (sem 9.89) $\mathrm{ng} / \mathrm{ml}$ in the oversupplememented group; $P<0 \cdot 01)$. However, when folate oversupplementation was carried out for a longer period $(60 \mathrm{~d})$, there was no further change in the folate level of the folate-oversupplemented group. However, the serum folate levels in the folate-oversupplemented group (146 (SEM 20) $\mathrm{ng} / \mathrm{ml}$ ) remained significantly higher compared with the control group $(65(\operatorname{sem~10\cdot 5)~ng/ml).~}$

\section{Folic acid transport across intestinal brush-border membrane vesicles}

Folic acid uptake across the intestinal BBM was significantly decreased $(26.9 \% ; P<0.05)$ in acute folate-oversupplemented group compared with the control group (Fig. 1). However, in the chronic folate-oversupplementated group, there was no significant change in folate transport compared with the control group. Furthermore, the kinetic characterisation of the transport of folic acid across intestinal BBMV was carried out in the acute folateoversupplemented group only.

\section{Kinetic characterisation of folic acid uptake across intestinal brush-border membrane vesicles}

BBMV from the control and folate-oversupplemented rats were incubated with $\left[{ }^{3} \mathrm{H}\right]$ folic acid, and the transport was studied at various time intervals, i.e. 10, 20, 30, 60, 120 and $240 \mathrm{~s}$ at $37^{\circ} \mathrm{C}$. The transport increased with an increase in time and an initial peak was observed within 20-30s in both groups of rats. At different time intervals

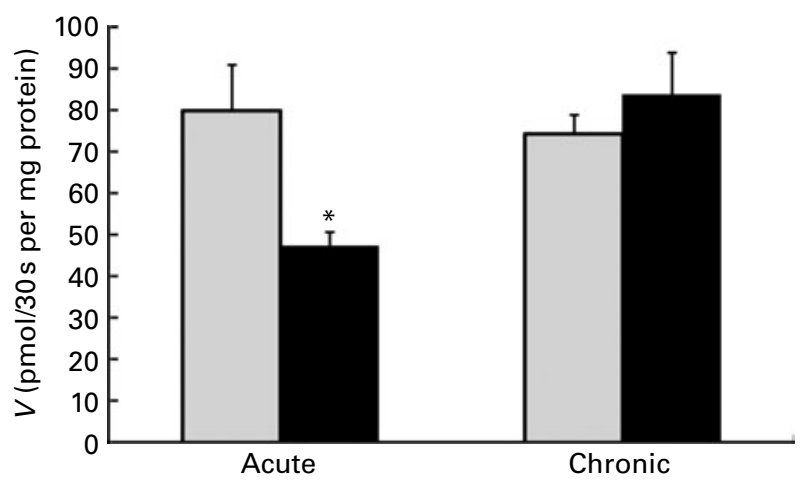

Fig. 1. $\left[{ }^{3} \mathrm{H}\right]$ Folic acid transport in intestinal brush-border membrane vesicles after acute and chronic folate oversupplementation. The incubation buffer (100 mm-NaCl, $80 \mathrm{~mm}$-mannitol, $10 \mathrm{~mm}$-HEPES, $10 \mathrm{~mm}$-2-morpholinoethanesulphonic acid, $\mathrm{pH} 5.5)$ containing $0.5 \mu \mathrm{M}-\left[{ }^{3} \mathrm{H}\right]$ folic acid was used for uptake measurements. Data are mean values with their standard errors ( $n$ 4), carried out in duplicate. * Mean value was significantly different from that of the control group $(P<0.05)$. $\square$, Control; $\mathbf{\square}$, oversupplemented. 
studied, the uptake was $27 \cdot 2$ to $56 \cdot 5 \%$ less in the folate-oversupplemented rats $(P<0 \cdot 01)$ (Fig. 2). In order to determine the driving force for folate transport across the intestinal BBM, the $\mathrm{pH}$ of the incubation buffer was varied from 5 to 8 , keeping the intravesicular $\mathrm{pH}$ constant at $7 \cdot 5$. As shown in Fig. 3, upon decreasing the incubation buffer $\mathrm{pH}$ from 7 to 5 , an increase in folic acid uptake was observed in both groups, with maximum uptake at $\mathrm{pH} 5.5$ in both groups of rats. Moreover, at the different $\mathrm{pH}$ points studied, the folic acid uptake was $15 \cdot 8$ to $41 \cdot 8 \%(P<0 \cdot 01)$ less in the oversupplemented group. Notably, no such uniform trend was observed in the $\mathrm{pH}$ range $7-8$. Furthermore, since the saturable kinetics is a notable characteristic feature of carrier-mediated transport, kinetic studies were performed in the presence of increasing concentrations of the substrate from $0 \cdot 125$ to $3 \cdot 0 \mu \mathrm{M}$. The initial velocity determined at $30 \mathrm{~s}$ and at $\mathrm{pH} 5.5$ showed that, in both groups, the saturation phenomenon with a plateau at $1.0 \mu \mathrm{m}$ of the substrate concentration was indicative of the MichaelisMenten kinetics (Fig. 4). At the physiological range of folic acid $(0-1.0 \mu \mathrm{M})$, the uptake was $12.9-29 \%$ less in the folate-oversupplemented group $(P<0.05)$. Further from the data, the kinetic constants $K_{\mathrm{m}}$ and $V_{\max }$ values were determined by the Lineweaver-Burk plot. $K_{\mathrm{m}}$ values for the control and folate-oversupplemented groups were found to be the same, i.e. $2 \cdot 85$ (SEm 0.12) $\mu$ m. However, the values of $V_{\max }$ for the control and folate-oversupplemented rats was 667 (SEM 17.3) and 500 (SEM 18.8) pmol/30 s per mg protein, respectively $(P<0 \cdot 01)$.

\section{Expression of mRNA corresponding to rRFC and rPCFT}

The findings that the folic acid uptake process is markedly decreased in intestinal BBMV with an appreciable

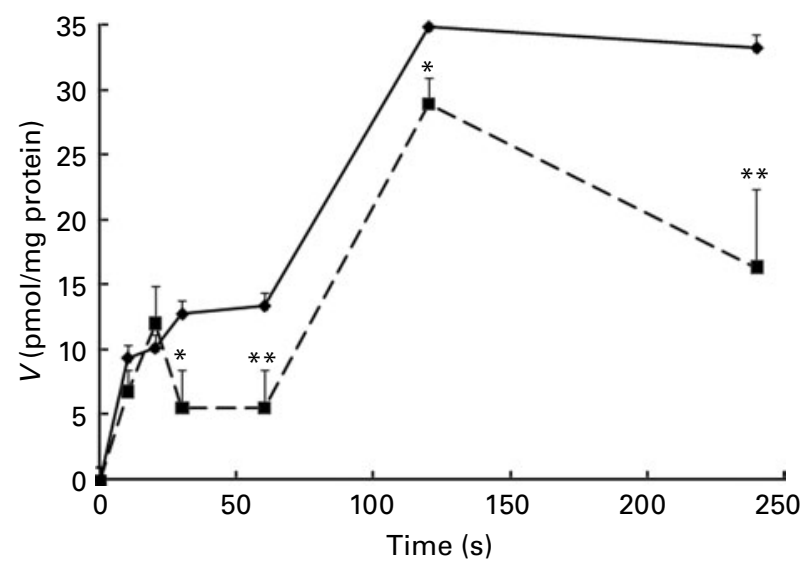

Fig. 2. $\left[{ }^{3} \mathrm{H}\right]$ Folic acid transport in intestinal brush-border membrane vesicles at different time intervals after acute folate oversupplementation. The incubation buffer (100 mM- $\mathrm{NaCl}, 80 \mathrm{~mm}$-mannitol, $10 \mathrm{~mm}-\mathrm{HEPES}, 10 \mathrm{~mm}$ 2-morpholinoethanesulphonic acid, pH 5.5) containing $0.5 \mu \mathrm{M}-\left[{ }^{3} \mathrm{H}\right]$ folic acid was used for uptake measurements at different time intervals. Data are mean values with their standard errors of four separate uptake determinations, carried out in duplicate. Mean values were significantly different from that of the control group: ${ }^{\star} P<0.05,{ }^{\star \star} P<0.01 .-\$-$, Control; $-\mathbf{-}-$, oversupplemented.

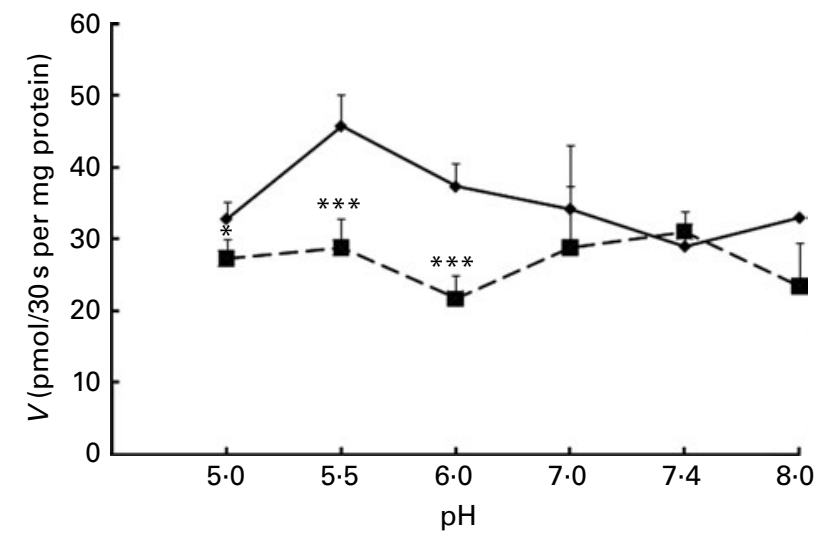

Fig. 3. $\left[{ }^{3} \mathrm{H}\right]$ Folic acid uptake in rat intestinal brush-border membrane vesicles as a function of $\mathrm{pH}$ optimum after acute folate oversupplementation. Uptake was measured by varying the incubation buffer $(100 \mathrm{~mm}-\mathrm{NaCl}$, $80 \mathrm{~mm}$-mannitol, $10 \mathrm{~mm}$-HEPES and $10 \mathrm{~mm}$-2-morpholinoethanesulphonic acid) with $\mathrm{pH}$ from 5.0 to 8.0 , keeping intravesicular $\mathrm{pH} 7.4$ at $0.5 \mu \mathrm{M}-\left[{ }^{3} \mathrm{H}\right]$ folic acid concentration for $30 \mathrm{~s}$. Data are mean values with their standard errors of four separate uptake determinations, carried out in duplicate. Mean values were significantly different from that of the control group: ${ }^{*} P<0.05$, ${ }^{\star \star \star} P<0.001$. $-\bullet-$, Control; $-\mathbf{-}-$, oversupplemented.

decrease in $V_{\max }$, i.e. the number of transporters in the folate-oversupplemented group compared with the control group, led us to determine the mRNA expression of folate transporters. For this purpose, RT-PCR analysis was performed using gene-specific primers for $\mathrm{r} R F C, \mathrm{r} P C F T$ and rGAPDH (as an internal control). The RT-PCR products were resolved on $1.2 \%$ agarose gel to observe the expression, and the band densities were quantified by densitometric analysis. It was deduced that there was no significant change in the expression of mRNA coding for $\mathrm{r} R F C$ and $\mathrm{rPCFT}$, both in the acute and chronic

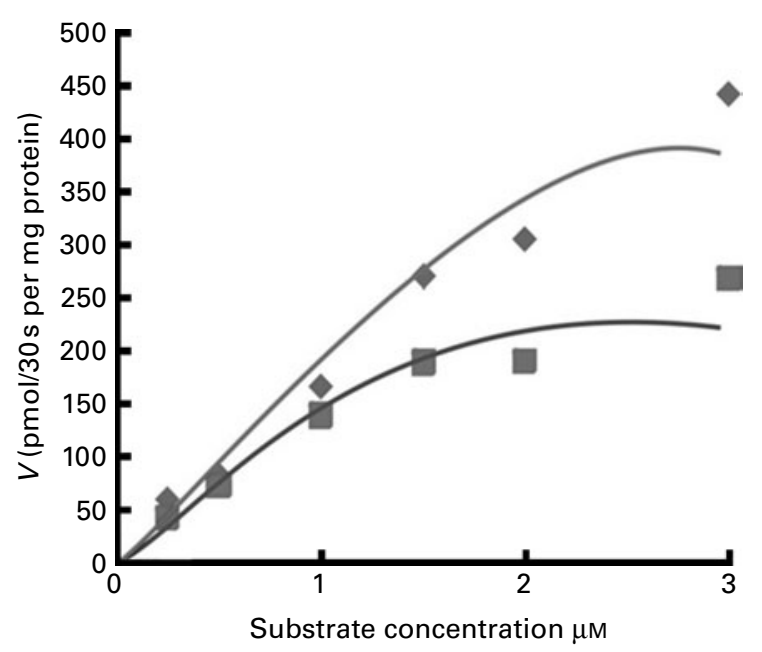

Fig. 4. $\left[{ }^{3} \mathrm{H}\right]$ Folic acid uptake in intestinal brush-border membrane vesicles as a function of substrate concentration after acute folate oversupplementation. Uptake was measured by varying $\left[{ }^{3} \mathrm{H}\right]$ folic acid concentration from 0.125 to $3.0 \mu \mathrm{M}$ in the incubation medium $(100 \mathrm{~mm}-\mathrm{NaCl}, 80 \mathrm{~mm}-$ mannitol, $10 \mathrm{~mm}-$ HEPES and $10 \mathrm{~mm}$-2-morpholinoethanesulphonic acid, pH 5.5) after incubating brush-border membrane vesicles for $30 \mathrm{~s}$. Data are mean values with their standard errors of four separate uptake determinations, carried out in duplicate. $\downarrow$, Control; $a$, oversupplemented. 
folate-oversupplemented groups compared with the control group (Figs. 5(a), (b) and 6(a), (b)).

Expression of anti-rat reduced folate carrier and anti-rat proton-coupled folate transporter in the brush-border membrane of the intestine

Since there was no significant change in the mRNA expression of folate transporters, the study was further extended to determine the regulation of folate transporters at the protein level. Western blot analysis was performed using specific polyclonal anti-rRFC and anti-rPCFT antibodies. The results showed a significant decrease in rRFC $(P<0.001)$ and rPCFT $(P<0.05)$ protein levels in BBMV isolated from the folate-oversupplemented rats compared with the control rats during acute folate oversupplementation (Fig. 5(c) and (d)). The decreased expression in the folate-oversupplemented group was to the extent of $33 \%$ in rRFC and $37 \%$ in rPCFT in intestinal BBMV. However, there was no significant change in the protein expression of rRFC and rPCFT in the chronic folate-oversupplemented group compared with the control group (Fig. 6(c) and (d)).

\section{Discussion}

The present study was carried out to determine the effect of short (acute) and long (chronic) term dietary folate oversupplementation on intestinal folic acid uptake. The study was carried out on the Wistar strain of rats, which were used earlier for folate deficiency studies ${ }^{(39)}$ and for determining the in vivo folate kinetics ${ }^{(31)}$. Folate oversupplementation in rats was carried out by feeding ten times of normal folic acid, i.e. $20 \mathrm{mg} / \mathrm{kg}$ diet for $10 \mathrm{~d}$ (acute group) and $60 \mathrm{~d}$ (chronic group). The folic acid level in the oversupplemented group corresponds to $900 \mu \mathrm{g} / \mathrm{d}$ of folic acid intake in humans ${ }^{(23)}$. The duration of acute and chronic treatments was chosen as per the previous reports ${ }^{(40-43)}$. Folate oversupplementation in rats for a period of 10 and $60 \mathrm{~d}$ did not significantly change their body weight. This is in agreement with previous reports ${ }^{(26)}$, where weanling rats were administered $40 \mathrm{mg}$ folic acid/ $\mathrm{kg}$ body weight for 4 weeks and no change in growth was observed compared with controls. Our feeding regimen was useful in inducing the folate-oversupplemented state in rats, as indicated by a significant increase $(2 \cdot 2$-fold) in serum folate levels of the folate-oversupplemented rats compared with the controls, in agreement with some previous results observing the same serum folate levels in controls ${ }^{(9,44)}$. Earlier, Achon et $a l .{ }^{(26)}$ have shown a threefold increase in serum folate levels upon feeding $40 \mathrm{mg}$ folic acid to rats for a period of 3 weeks. Such an increase in folic acid concentration has been shown to decrease natural killer cell cytotoxicity and to reduce the response to antifolate drugs used against malaria and other diseases ${ }^{(45)}$. Besides, this increase in serum folate levels might also have detrimental effects on one-carbon metabolism, leading to an increase in $S$-adenosylmethionine, an important contributor of methyl group for methylation reactions, and thereby might down-regulate the expression of tumour-suppressor genes.

Folate uptake in intestinal BBMV follows saturable kinetics and has a $\mathrm{pH}$ optimum at 5.5, in agreement with the previous reports from our laboratory ${ }^{(34)}$ as well as from other laboratories ${ }^{(3,46)}$, suggesting that acidic $\mathrm{pH}$ is a potential driving force of folate transport across the BBM surface. The present results on folate uptake in the intestinal BBMV isolated from the folate-oversupplemented (a)

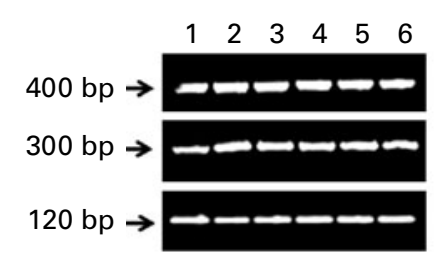

(c)

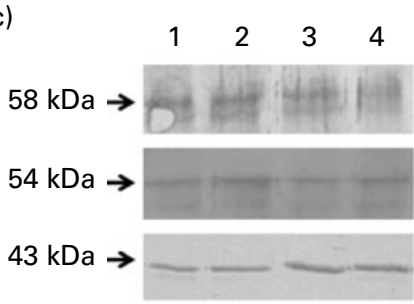

(b)

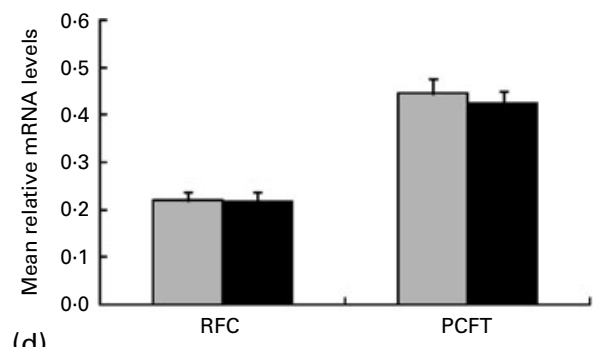

(d)

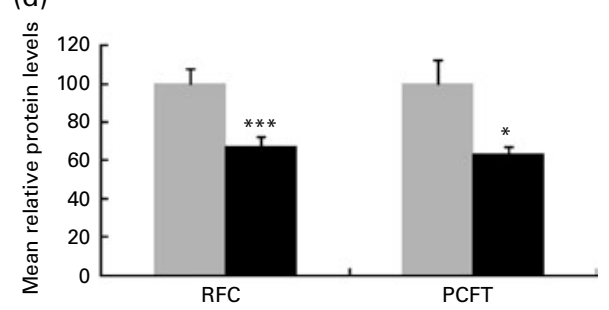

Fig. 5. RT-PCR analysis of anti-rat reduced folate carrier (rRFC), anti-rat proton-coupled folate transporter (rPCFT) and anti-rat glyceraldehyde 3-phosphate dehydrogenase (rGAPDH) as an internal control in jejunal tissues (a) resolved on $1.2 \%$ agarose gel electrophoresis and (b) densitometric analysis representing a relative change in rRFC and rPCFT mRNA expressions. Data shown are mean of four separate sets of experiments. (a) Lanes 1-3: control ( $\square$ ); 4-6: acute folate-oversupplemented ( $\square$ ); Western blot analysis of intestinal BBM vesicle (c) using anti-rRFC (58 kDa), anti-rPCFT (54 kDa) and anti-rat $\beta$-actin (43kDa) antibodies and (d) densitometric analysis representing a relative change in rRFC and rPCFT protein levels. Data shown are mean of four separate sets of experiments. (c) Lanes 1 and 2: control ( $\square$ ); 3 and 4: acute folate-oversupplemented ( $\square$ ). Mean values were significantly different from that of the control group: ${ }^{\star} P<0.05,{ }^{\star \star \star} P<0.001$. 
(a)

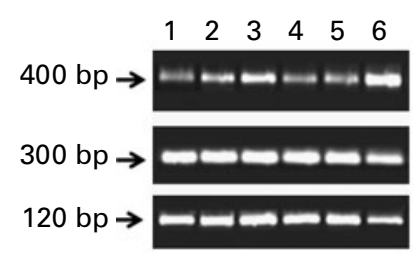

(c)

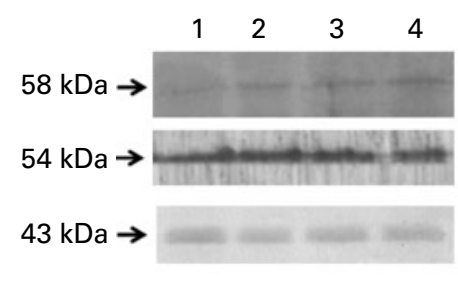

(b)

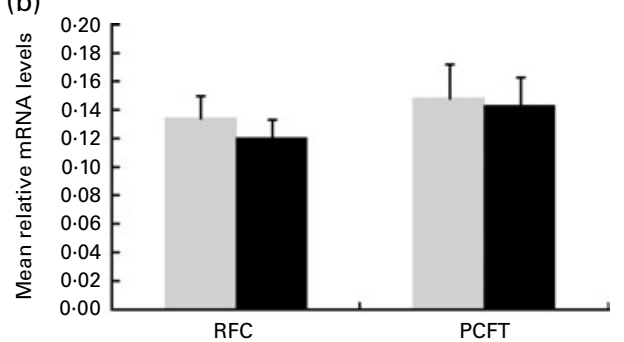

(d)

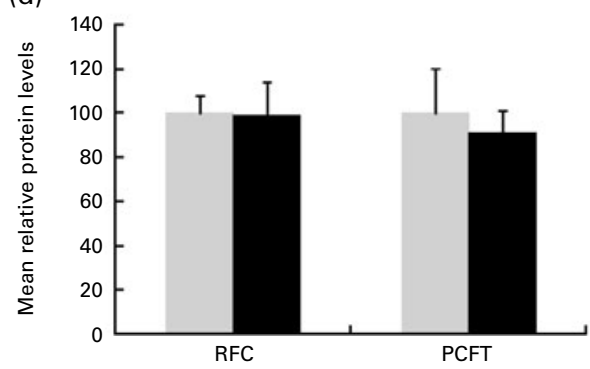

Fig. 6. RT-PCR analysis of anti-rat reduced folate carrier (rRFC), anti-rat proton-coupled folate transporter (rPCFT) and anti-rat glyceraldehyde 3-phosphate dehydrogenase ( $\mathrm{rGAPDH}$ ) as an internal control in jejunal tissues (a) resolved on $1.2 \%$ agarose gel electrophoresis and (b) densitometric analysis representing a relative change in rRFC and rPCFT mRNA expressions. Data shown are mean of four separate sets of experiments. (a) Lanes 1-3: control ( $\square$ ); 4-6: chronic folate-oversupplemented ( $\mathbf{\square})$; Western blot analysis of intestinal BBM vesicle (c) using anti-rRFC (58 kDa), anti-rPCFT (54 kDa) and anti-r $\beta$-actin ( $43 \mathrm{kDa})$ antibodies and (d) densitometric analysis representing a relative change in rRFC and rPCFT protein levels. Data shown are mean of four separate sets of experiments. (c) Lanes 1 and 2: control $(\square)$; 3 and 4: chronic folate-oversupplemented $(\square)$.

rats showed that acute folate oversupplementation leads to a significant down-regulation in intestinal folate uptake at acidic pH optima. However, during chronic folate oversupplementation, there was no significant change in intestinal folate uptake. This observed decrease in folate uptake during acute folate oversupplementation was associated with a decrease in $V_{\max }$ without any significant change in the $K_{\mathrm{m}}$ of folate uptake process, indicating that folate oversupplementation decreased folate uptake by decreasing the number or activity of folate transporters without altering the affinity of transporters towards its substrate. Moreover, the $K_{\mathrm{m}}$ values obtained were similar to the values observed earlier ${ }^{(34,35)}$.

In order to evaluate the mechanism of the downregulation of folate uptake, the expression of the folate transporters RFC and PCFT was of prime importance, as both are suggested to have a role in intestinal folate uptake $^{(8,47)}$. We found that there was no significant change in $\mathrm{r} R F C$ and $\mathrm{r} P C F T$ mRNA levels in the small intestine between the folate-oversupplemented rats and control rats during acute as well as chronic folate oversupplementation. Therefore, the results deduce that the expression of transporters, i.e. rRFC and rPCFT, are not regulated at the transcriptional level, suggesting a different regulatory point for decreased folate uptake during acute folate oversupplementation. The down-regulation of intestinal folate uptake during acute folate oversupplementation was found to be associated with a parallel decrease in the protein levels of both RFC and PCFT transporters, suggesting the possible involvement of a post-transcriptional or translational regulatory mechanism in regulating intestinal folate uptake. However, during chronic folate oversupplementation, there was no significant change in the protein expression of rRFC and rPCFT. Earlier studies by Ashokkumar et al. ${ }^{(29)}$ have shown that the carrier-mediated uptake of $\left[{ }^{3} \mathrm{H}\right]$ folic acid at $\mathrm{pH} 5.5$ by Caco- 2 and $\mathrm{HK}-2$ cells was significantly lower when cells were cultured in folate-oversupplemented condition for five generations This reduction in folic acid uptake was associated with a significant decrease in the mRNA and protein levels of the hRFC and was associated with a decrease in mRNA levels of PCFT. The present results are not in complete agreement with those of Ashokkumar et al. ${ }^{(29)}$. The differences might be due to the differences in models studied, as they have used an in vitro model for their study in comparison with our in vivo rat model. Recently, a study by Jing et al. ${ }^{(30)}$ has found that jejunal mRNA levels of $R F C$ were decreased in hens fed with 5-methyltetrahydrofolate $(11.30 \mathrm{mg} / \mathrm{kg}$ diet for $21 \mathrm{~d})$, but not in hens fed with a folic acid diet $(10 \mathrm{mg} / \mathrm{kg}$ diet for $21 \mathrm{~d})$. The variations in the amount of folic acid in the diet, duration of treatment and species studied seem to be responsible for the different results achieved in different studies. In the present study, folic acid supplementation increased the serum folate levels, which could be sensed by the folate transport regulatory systems that led to a decrease in the expression of folate transporters.

\section{Conclusions}

The results of the present investigation showed that, initially, folate oversupplementation for a short period 
resulted in a significant down-regulation of intestinal folate uptake, by decreasing the number of transporters without any change in the specificity of folate transporters towards its substrate. The observed down-regulation was associated with a significant decrease in rRFC and rPCFT expressions, suggesting a post-transcriptional or translational regulation of folate uptake during folate oversupplementation. When oversupplementation was continued for a longer period, the intestinal folate transport and the expression of transporters remained unaltered compared with the control. Notably, the serum folate levels remained $2 \cdot 2$-fold higher under these conditions, thus exposing the cells to a high concentration of unmetabolised folic acid. The question whether the presence of unmetabolised folic acid in blood could interfere with various folate-dependent biochemical reactions needs to be addressed in future studies.

\section{Acknowledgements}

There is no funding agency supporting this work. S. D. carried out the animal study, transport study, prepared BBMV from animals for gene expression analyses and performed the statistical analysis. N. A. W. carried out RT-PCR, Western blotting and helped to draft the manuscript. J. K. conceived of the study and participated in its design and coordination. All authors declare that there are no potential conflicts of interest. All authors read and approved the final manuscript.

\section{References}

1. Stanger O (2002) Physiology of folic acid in health and disease. Curr Drug Metab 3, 211-223.

2. Wani NA, Hamid A \& Kaur J (2008) Folate status in various pathophysiological conditions. IUBMB Life 60, 834-842.

3. Qiu A, Jansen M, Sakaris A, et al. (2006) Identification of an intestinal folate transporter and the molecular basis for hereditary folate malabsorption. Cell 127, 917-928.

4. Said HM \& Mohammadkhani R (1993) Folate transport in intestinal brush border membrane: involvement of essential histidine residue(s). Biochem J 290, Pt 1, 237-240.

5. Hamid A \& Kaur J (2007) Long-term alcohol ingestion alters the folate-binding kinetics in intestinal brush border membrane in experimental alcoholism. Alcohol 41, 441-446.

6. Hamid A, Wani NA \& Kaur J (2009) New perspectives on folate transport in relation to alcoholism-induced folate malabsorption - association with epigenome stability and cancer development. FEBS J 276, 2175-2191.

7. Moscow JA, Gong M, He R, et al. (1995) Isolation of a gene encoding a human reduced folate carrier (RFC1) and analysis of its expression in transport-deficient, methotrexate-resistant human breast cancer cells. Cancer Res 55, 3790-3794.

8. Matherly LH \& Goldman DI (2003) Membrane transport of folates. Vitam Horm 66, 403-456.

9. Hamid A, Wani NA, Rana S, et al. (2007) Down-regulation of reduced folate carrier may result in folate malabsorption across intestinal brush border membrane during experimental alcoholism. FEBS J 274, 6317-6328.

10. Nabokina SM, Ma TY \& Said HM (2004) Mechanism and regulation of folate uptake by human pancreatic epithelial MIA PaCa-2 cells. Am J Physiol Cell Physiol 287, C142-C148.
11. Hamid A \& Kaur J (2006) Chronic alcoholism alters the transport characteristics of folate in rat renal brush border membrane. Alcohol 38, 59-66.

12. Whetstine JR, Flatley RM \& Matherly LH (2002) The human reduced folate carrier gene is ubiquitously and differentially expressed in normal human tissues: identification of seven non-coding exons and characterization of a novel promoter. Biochem J 367, 629-640.

13. Bosson G (2003) Reduced folate carrier: biochemistry and molecular biology of the normal and methotrexate-resistant cell. Br J Biomed Sci 60, 117-129.

14. Wang X, Shen F, Freisheim JH, et al. (1992) Differential stereospecificities and affinities of folate receptor isoforms for folate compounds and antifolates. Biochem Pharmacol 44, 1898-1901.

15. Hamid A \& Kaur J (2007) Decreased expression of transporters reduces folate uptake across renal absorptive surfaces in experimental alcoholism. J Membr Biol 220, 69-77.

16. Czeizel AE (2000) Primary prevention of neural-tube defects and some other major congenital abnormalities: recommendations for the appropriate use of folic acid during pregnancy. Paediatr Drugs 2, 437-449.

17. Butterworth CE Jr \& Bendich A (1996) Folic acid and the prevention of birth defects. Annu Rev Nutr 16, 73-97.

18. Botto LD, Mulinare J \& Erickson JD (2002) Occurrence of omphalocele in relation to maternal multivitamin use: a population-based study. Pediatrics 109, 904-908.

19. Glynn SA, Albanes D, Pietinen P, et al. (1996) Colorectal cancer and folate status: a nested case-control study among male smokers. Cancer Epidemiol Biomarkers Prev 5, 487-494.

20. Lashner BA, Provencher KS, Seidner DL, et al. (1997) The effect of folic acid supplementation on the risk for cancer or dysplasia in ulcerative colitis. Gastroenterology 112, 29-32.

21. Bailey LB, Rampersaud GC \& Kauwell GP (2003) Folic acid supplements and fortification affect the risk for neural tube defects, vascular disease and cancer: evolving science. J Nutr 133, 1961S-1968S

22. Ulrich CM \& Potter JD (2006) Folate supplementation: too much of a good thing? Cancer Epidemiol Biomarkers Prev 15, 189-193.

23. Choumenkovitch SF, Selhub J, Wilson PW, et al. (2002) Folic acid intake from fortification in United States exceeds predictions. J Nutr 132, 2792-2798.

24. Czernichow S, Noisette N, Blacher J, et al. (2005) Case for folic acid and vitamin $\mathrm{B}_{12}$ fortification in Europe. Semin Vasc Med 5, 156-162.

25. Song J, Medline A, Mason JB, et al. (2000) Effects of dietary folate on intestinal tumorigenesis in the apcMin mouse. Cancer Res 60, 5434-5440.

26. Achon M, Reyes L, Alonso-Aperte E, et al. (1999) High dietary folate supplementation affects gestational development and dietary protein utilization in rats. J Nutr 129, 1204-1208.

27. Troen AM, Mitchell B, Sorensen B, et al. (2006) Unmetabolized folic acid in plasma is associated with reduced natural killer cell cytotoxicity among postmenopausal women. J Nutr 136, 189-194.

28. Ebbing M, Bonaa KH, Arnesen E, et al. (2010) Combined analyses and extended follow-up of two randomized controlled homocysteine-lowering B-vitamin trials. J Intern Med (Epublication ahead of print version 4 August 2010).

29. Ashokkumar B, Mohammed ZM, Vaziri ND, et al. (2007) Effect of folate oversupplementation on folate uptake by human intestinal and renal epithelial cells. Am J Clin Nutr 86, 159-166

30. Jing M, Tactacan GB, Rodriguez-Lecompte JC, et al. (2009) Molecular cloning and tissue distribution of reduced folate carrier and effect of dietary folate supplementation on the 
expression of reduced folate carrier in laying hens. Poult Sci 88, 1939-1947.

31. Steinberg SE, Campbell C \& Hillman RS (1981) A new animal model for studies of in vivo folate kinetics. Am J Physiol 241, G516-G519.

32. Weiser MM (1973) Intestinal epithelial cell surface membrane glycoprotein synthesis. I. An indicator of cellular differentiation. J Biol Chem 248, 2536-2541.

33. Kessler M, Acuto O, Storelli C, et al. (1978) A modified procedure for the rapid preparation of efficiently transporting vesicles from small intestinal brush border membranes. Their use in investigating some properties of D-glucose and choline transport systems. Biochim Biophys Acta 506, 136-154.

34. Hamid A, Kaur J \& Mahmood A (2007) Evaluation of the kinetic properties of the folate transport system in intestinal absorptive epithelium during experimental ethanol ingestion. Mol Cell Biochem 304, 265-271.

35. Hamid A, Kiran M, Rana S, et al. (2009) Low folate transport across intestinal basolateral surface is associated with downregulation of reduced folate carrier in in vivo model of folate malabsorption. IUBMB Life 61, 236-243.

36. Yasuda S, Hasui S, Yamamoto C, et al. (2008) Placental folate transport during pregnancy. Biosci Biotechnol Biochem 72, $2277-2284$.

37. Towbin H, Staehelin T \& Gordon J (1992) Electrophoretic transfer of proteins from polyacrylamide gels to nitrocellulose sheets: procedure and some applications. 1979. Biotechnology 24, 145-149.

38. Said HM, Chatterjee N, Haq RU, et al. (2000) Adaptive regulation of intestinal folate uptake: effect of dietary folate deficiency. Am J Physiol Cell Physiol 279, C1889-C1895.
39. Hamid A \& Kaur J (2009) Role of signaling pathways in the regulation of folate transport in ethanol-fed rats. $J$ Nutr Biochem 20, 291-297.

40. de Oliveira MR, Silvestrin RB, Mello e Souza T, et al. (2008) Therapeutic vitamin A doses increase the levels of markers of oxidative insult in substantia nigra and decrease locomotory and exploratory activity in rats after acute and chronic supplementation. Neurochem Res 33, 378-383.

41. Manso MA, Rebollo A, Pescador R, et al. (1995) Action of CCK on CDE diet-induced acute pancreatitis in rats treated with hydrocortisone. Comp Biochem Physiol C Pharmacol Toxicol Endocrinol 111, 257-263.

42. Montesano R, Bresil H, Planche-Martel G, et al. (1980) Effect of chronic treatment of rats with dimethylnitrosamine on the removal of $\mathrm{O}_{6}$-methylguanine from DNA. Cancer Res $\mathbf{4 0}$, 452-458.

43. Reul JM, Stec I, Soder M, et al. (1993) Chronic treatment of rats with the antidepressant amitriptyline attenuates the activity of the hypothalamic-pituitary-adrenocortical system. Endocrinology 133, 312-320.

44. Vitale JJ \& Hegsted DM (1967) Vitamin $B_{12}$ deficiency in the rat: effect on serum folate and liver formiminotransferase activity. Am J Clin Nutr 20, 311-316.

45. Smith AD, Kim YI \& Refsum H (2008) Is folic acid good for everyone? Am J Clin Nutr 87, 517-533.

46. Chiao JH, Roy K, Tolner B, et al. (1997) RFC-1 gene expression regulates folate absorption in mouse small intestine. J Biol Chem 272, 11165-11170.

47. Matherly LH, Hou Z \& Deng Y (2007) Human reduced folate carrier: translation of basic biology to cancer etiology and therapy. Cancer Metastasis Rev 26, 111-128. 